\section{Improving Spinach, Radish, and Lettuce Growth under Red Light- emitting Diodes (LEDs) with Blue Light Supplementation}

\author{
Neil C. Yorio ${ }^{1}$, Gregory D. Goins, and Hollie R. Kagie \\ Dynamac Corporation, Mail Code DYN-3, Kennedy Space Center, FL 32899
}

\author{
Raymond M. Wheeler and John C. Sager \\ NASA Biomedical Operations Office, Mail Code YA-D3, Kennedy Space \\ Center, FL 32899
}

Additional index words. spectral quality, Spinacea oleracea, Raphanus sativus, Lactuca sativa, bioregenerative life support systems, photomorphogenesis

Abstract. Radish (Raphanus sativus L. cv. Cherriette), lettuce (Lactuca sativa L. cv. Waldmann's Green), and spinach (Spinacea oleracea L. cv. Nordic IV) plants were grown under 660-nm red light-emitting diodes (LEDs) and were compared at equal photosynthetic photon flux $(P P F)$ with either plants grown under cool-white fluorescent lamps (CWF) or red LEDs supplemented with $10 \%\left(30 \mu \mathrm{mol} \cdot \mathrm{m}^{-2} \cdot \mathrm{s}^{-1}\right)$ blue light $(400-500 \mathrm{~nm})$ from blue fluorescent (BF) lamps. At 21 days after planting (DAP), leaf photosynthetic rates and stomatal conductance were greater for plants grown under CWF light than for those grown under red LEDs, with or without supplemental blue light. At harvest (21 DAP), total dry-weight accumulation was significantly lower for all species tested when grown under red LEDs alone than when grown under CWF light or red LEDs $+10 \%$ BF light. Moreover, total dry weight for radish and spinach was significantly lower under red LEDs $+10 \%$ BF than under CWF light, suggesting that addition of blue light to the red LEDs was still insufficient for achieving maximal growth for these crops.

Studies of crop plants to provide food, atmospheric regeneration, water purification, and waste recycling for long duration space missions or extraterrestrial habitations have been a focus for NASA's Advanced Life Support project for a number of years (MacElroy and Bredt, 1985; Olson et al., 1988; Salisbury and Bugbee, 1988). Controlling and supplying a sufficient quantity and quality of light will be a significant challenge for growing plants in space (Bugbee and Salisbury, 1988; Langhans and Dreesen, 1988; Sager and Wheeler, 1992). Light-emitting diodes (LEDs) are a promising electric light source for space-based plant growth chambers because of their small mass and volume, solid-state construction, superior

Received for publication 13 Dec. 1999. Accepted for publication 1 Sept. 2000. This research was supported by NASA Contract NAS10-12180 to Dynamac Corporation. We gratefully acknowledge Cheryl L. Mackowiak and Lisa M. Ruffe for horticultural assistance on conducting these studies, and Tracy A.O. Dougher for critical review of the manuscript. Mention of a trade name or proprietary product does not constitute an endorsement, guarantee, or warranty by either Dynamac Corporation or National Aeronautics and Space Administration. Quantum Devices, Inc., Barneveld, Wis., holds a patent (no. 5,012,609) on light-emitting diodes as an illumination source for plant growth. The cost of publishing this paper was defrayed in part by the payment of page charges. Under postal regulations, this paper therefore must be hereby marked advertisement solely to indicate this fact.

${ }^{1}$ To whom reprint requests should be addressed. Email address: neil.yorio-1@ksc.nasa.gov blue fluorescent (red $+\mathrm{BF}$ ), and red LEDs only. from spectroradiometric data. measurements taken at the top of the plant canopy. with a spectroradiometer (Barnes et al., 1993). available red LEDs emit a narrow-spectrum of light $(660 \mathrm{~nm}$ with $25 \mathrm{~nm}$ bandwidth at halfpeak height), which closely matches a peak absorbance of chlorophyll (McCree, 1972).

Although red LEDs have great potential for use as a light source to drive photosynthesis, plants are adapted to utilize a wide-spectrum of light to control photomorphogenesis (Briggs, 1993). Previous reports indicate that a minimum amount $\left(20-30 \mu \mathrm{mol} \cdot \mathrm{m}^{-2} \cdot \mathrm{s}^{-1}\right)$ of blue light in broad-spectrum lamps is necessary to achieve normal growth and morphology (Barnes and Bugbee, 1992; Britz and Sager, 1990; Wheeler et al., 1991; Yorio et al., 1995). This blue light requirement appears to be a species-specific response (Dougher and Bugbee, 1998; Yorio et al., 1998). Tests with the addition of blue fluorescent (BF) light to narrow-band red LEDs $(660 \mathrm{~nm})$ support the findings with broad-spectrum lamps (Brown et al., 1995; Bula et al., 1991; Goins et al., 1997; Goins et al., 1998; Hoenecke et al., 1992). Despite the increasing popularity of red LEDs as a radiation source for growing plants, information is available for only a few plant species that directly compares growth and yield under red LEDs (with and without supplemental blue light) vs. broad spectrum light. Hence, the goal of this research was to investigate the growth, development, and edible biomass partitioning of three common salad crops (lettuce, spinach, and radish) grown under red LEDs with and without supplemental blue fluorescent lighting to determine the efficacy of this promising radiation source. Testing these plant species with LEDs also fulfills NASA's near-term goal of investigating the incorporation of salad-type crops in a space station salad machine scenario, which may utilize LEDs as a radiation source (Salisbury and Clark, 1996). To our knowledge, responses of spinach and radish to LEDs

Table 1. Photosynthetic photon flux $(P P F)$ measurements, red and blue bandwidth integrations, and yield photon flux (YPF) for cool-white fluorescent lamps (CWF), red LEDs $(660 \mathrm{~nm})+10 \%\left(30 \mu \mathrm{mol} \cdot \mathrm{m}^{-2} \cdot \mathrm{s}^{-1}\right)$

\begin{tabular}{|c|c|c|c|}
\hline \multirow[b]{2}{*}{ Measurement } & \multicolumn{3}{|c|}{ Light source } \\
\hline & $\mathrm{CWF}^{\mathrm{z}}$ & $\operatorname{Red}+\mathrm{BF}^{\mathrm{y}, \mathrm{x}}$ & Red LEDs ${ }^{\mathrm{z}, x}$ \\
\hline & \multicolumn{3}{|c|}{ Radish } \\
\hline Blue photon flux $(400-500 \mathrm{~nm})$ & 50 & $31(2)$ & 0 \\
\hline Red photon flux $(600-700 \mathrm{~nm})$ & 84 & $269(33)$ & 308 \\
\hline Total PPF $(400-700 \mathrm{~nm})^{\mathrm{y}}$ & $308(14)$ & $300(33)$ & $308(35)$ \\
\hline \multirow[t]{2}{*}{ YPF $(350-750 \mathrm{~nm})^{\mathrm{w}}$} & 269 & 270 & 283 \\
\hline & \multicolumn{3}{|c|}{ Spinach } \\
\hline Blue photon flux (400-500 nm) & 47 & $30(1)$ & 0 \\
\hline Red photon flux $(600-700 \mathrm{~nm})$ & 80 & $253(22)$ & 275 \\
\hline Total PPF (400-700 nm) & $291(11)$ & $283(22)$ & $275(24)$ \\
\hline \multirow[t]{2}{*}{ YPF (350-750 nm) } & 254 & 255 & 252 \\
\hline & \multicolumn{3}{|c|}{ Lettuce } \\
\hline Blue photon flux (400-500 nm) & 52 & $30(2)$ & 0 \\
\hline Red photon flux $(600-700 \mathrm{~nm})$ & 87 & $265(38)$ & 280 \\
\hline Total PPF (400-700 nm) & $317(23)$ & $295(37)$ & $280(31)$ \\
\hline YPF (350-750 nm) & 276 & 265 & 257 \\
\hline
\end{tabular}

${ }^{\mathrm{z}}$ Red and blue photon flux bandwidth integration values for CWF and Red LED treatments were calculated

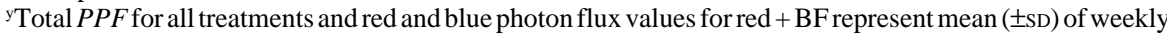

${ }^{x}$ Total $P P F$ for red LEDs and red photon flux for red $+B F$ were determined with a quantum sensor calibrated

${ }^{w}$ YPF values were calculated from relative quantum efficiency data in Sager et al. (1988) over the wavelength range of 350-750 $\mathrm{nm}$ as determined by McCree (1972). 
have not been tested. Lettuce has been tested with red LEDs for seedling response to blue light (Hoenecke et al., 1992), and a longer test without a concurrent broad-spectrum control has been performed (Bula et al., 1991).

\section{Materials and Methods}

Cultural conditions. All plants were grown hydroponically using nutrient film technique (Graves, 1981) with a modified half-strength Hoagland's solution (Hoagland and Arnon, 1950). Radish and lettuce plants were started by directly sowing dry seed between two Nitex (Tetko, Inc., Depew, N.Y.) nylon fabric wicks supported above the culture trays. Spinach seeds were incubated at $4{ }^{\circ} \mathrm{C}$ on moistened germination paper for $7 \mathrm{~d}$ and germinated seeds were sown as described for radish and lettuce. Each plastic culture tray $(10-\mathrm{cm} \mathrm{W} \times$ $35-\mathrm{cm} \mathrm{L}$ ) contained three plants spaced $12 \mathrm{~cm}$ apart (effective planting density of 75 plants per $\mathrm{m}^{2}$ ). Each treatment consisted of three separate culture trays spaced $2 \mathrm{~cm}$ apart (nine plants per treatment), which shared a common 10-L nutrient solution reservoir. Evapotranspiration losses of water were replenished daily by adding deionized water to the nutrient solution reservoir. Nutrient solution electrical conductivity was maintained at $\approx 1200 \mu \mathrm{S} \cdot \mathrm{cm}^{-1}$ by adding concentrated modified Hoagland's stock solution. Nutrient solution $\mathrm{pH}$ was continually monitored and maintained near 5.8 with additions of $0.1 \mathrm{M} \mathrm{HNO}_{3}$. Air temperature, relative humidity, and $\mathrm{CO}_{2}$ levels were maintained in growth chambers at $\approx 23{ }^{\circ} \mathrm{C}$, $65 \%$, and $1200 \mu \mathrm{mol} \cdot \mathrm{mol}^{-1}$, respectively.

Light treatments. Each lighting treatment was contained within separate controlled-environment chambers (Conviron PGW-36) to minimize spectral interference between treatments. All plants were grown for $21 \mathrm{~d}$ with photosynthetic photon flux $(P P F)$ maintained near $300 \mu \mathrm{mol} \cdot \mathrm{m}^{-2} \cdot \mathrm{s}^{-1}$. Levels of $P P F$ were measured with a quantum sensor (model LI180; LI-COR, Lincoln, Nebr.) calibrated with a spectroradiometer (model LI-1800,LI-COR) to enable accurate readings for LEDs (Barnes et al., 1993). Mean experimental $P P F$ and yield photon flux (YPF) (Sager et al., 1988) were calculated for each light treatment (Table 1). A photoperiod of 18-h light/6-h dark was used for radish and lettuce, and 12-h light/ 12-h dark for spinach. The spectral distributions for the three light treatments are shown in Fig. 1. For the red LED treatment, plants were grown under arrays equipped with discrete-type red gallium-aluminum-arsenide (GaAlAs) LEDs (Fig. 1A). For the red + blue light-supplemented treatments, blue fluorescent lamps (20-W F20T12/BB; Philips Lighting Co., Somerset, N.J.) supplied $\approx 10 \%$ (Fig. $1 \mathrm{~B})$ of the total $P P F$. Control plants were grown under broad-spectrum lamps (Fig. 1C; VHO cool-white fluorescent) that provided $\approx 16 \%\left(48 \mu \mathrm{mol} \mathrm{m}^{-2} \cdot \mathrm{s}^{-1} P P F\right)$ in the blue region of the spectrum (400-500 nm).

Plant measurements. At $21 \mathrm{~d}$ after planting (DAP) and $2 \mathrm{~h}$ after the onset of the photoperiod, leaf net photosynthesis (Pn) and stomatal conductance were measured from three

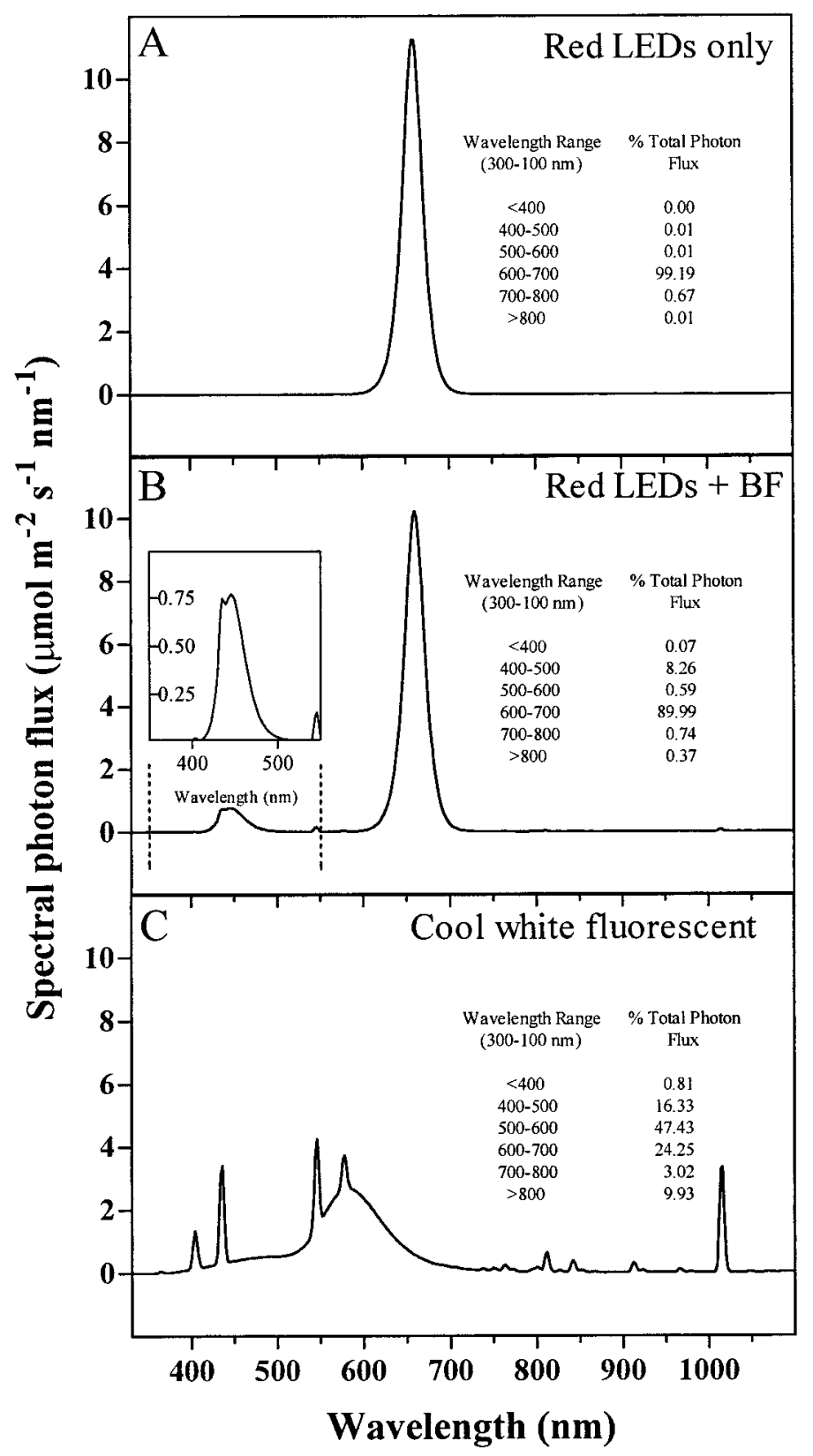

Fig. 1. Spectral distribution of light treatments used, including red LEDs only, red LEDs $+10 \%$ (30 $\left.\mu \mathrm{mol} \cdot \mathrm{m}^{-2} \cdot \mathrm{s}^{-1} P P F\right)$ blue fluorescent (red LEDs $+\mathrm{BF}$ ), and cool-white fluorescent. Photosynthetic photon flux integrations for each light treatment were equal to $300 \mu \mathrm{mol} \cdot \mathrm{m}^{-2} \cdot \mathrm{s}^{-1}$.

typical, fully expanded canopy leaves per light treatment, using a portable photosynthesis meter (model LI-6200, LI-COR) and steadystate porometer (model LI-1600, LI-COR), respectively. Chlorophyll samples were obtained from the same leaves on which the Pn and conductance measurements were taken, and analyzed by the colorimetric method of Wintermans and De Mots (1965). Plants were harvested at 21 DAP and immediately divided into shoot tissue (leaves, petioles, and stems), roots, and storage roots (for radish). Plant tissues were oven-dried at $70{ }^{\circ} \mathrm{C}$ for $72 \mathrm{~h}$ to determine dry weight (DW). Each experimental run was repeated once, and growth measurements represent means of 18 plants (two reps consisting of nine plants each). Singleleaf net photosynthetic rates and stomatal conductance represent means of six leaves (two reps consisting of three plants each). All data were analyzed by ANOVA (SPSS for Windows, version 6.1.3) and Tukey's HSD mean comparison procedure $(P \leq 0.05)$.

\section{Results and Discussion}

For each species, dry-weight accumulation (shoot, storage root, or root) was lower when plants were grown under red LEDs in comparison with plants grown under red LEDs $+10 \%$ BF light or CWF light (Fig. 2). Lettuce shoot DW was not significantly affected by red LED $+10 \% \mathrm{BF}$, indicating that good growth for lettuce could be achieved with only red and blue photons. Bula et al. (1991) reported similar results for lettuce cv. Grand Rapids when plants were grown with red LEDs $+10 \%$ BF. Several reports suggest that a 
minimum blue light requirement of $\approx 30$ $\mu \mathrm{mol} \cdot \mathrm{m}^{-2} \cdot \mathrm{s}^{-1}$ is necessary for normal development in several species (Hoenecke et al., 1992; Wheeler et al., 1991; Yorio et al., 1995, 1998), which generally agrees with our results for lettuce.

Dry-weight accumulation of radish and spinach increased significantly when red LEDs were supplemented with blue light, but plants grown under white (CWF) light showed the greatest production of DW (Fig. 2), indicating that these species may have a higher blue photon requirement than does lettuce. Alternatively, the red + BF treatment may be lacking some other wavelengths needed for optimal growth. The lack of significant storage root development in our tests for radish (Fig. 2) grown under red LEDs is consistent with previous observations for radish grown under red light without blue supplementation; this response has been associated with diminished sink demand of this tissue, mediated by reduced levels of cytokinins (Bukhov et al., 1996).

Hoenecke et al. (1992) reported that lettuce hypocotyl elongation under $24 \mu \mathrm{mol} \cdot \mathrm{m}^{-2} \cdot \mathrm{s}^{-1}$ blue light (400-500 $\mathrm{nm}$ ) from broad-spectrum CWF lamps was equivalent to that under $\approx 35$ $\mu \mathrm{mol} \cdot \mathrm{m}^{-2} \cdot \mathrm{s}^{-1}$ blue light provided from blue fluorescent lamps. This growth response suggests that the differences observed between light treatments may be a result of differing effects on the blue-light absorbing pigments, given the slightly greater amount of ultraviolet (UV) radiation and other non-blue wavelengths from CWF lamps. Indeed, the spectra of the lamps used in our study varied considerably with regard to non-blue wavelengths (Fig. 1), and Senger (1984) has suggested that UV light may be as effective as blue light for some responses. Also, the small amount of far-red radiation in the CWF lamps could contribute to the response by affecting phytochrome. However, the phytochrome photostationary states calculated for all lamp treatments used in these tests were $\geq 0.84$ (data not shown), near the maximum of 0.89 , indicating that any phytochrome involvement in the spectral responses observed in these studies would probably be negligible (Sager et al., 1988). Furthermore, the CWF treatment in our study provided $48 \mu \mathrm{mol} \cdot \mathrm{m}^{-2} \cdot \mathrm{s}^{-1}$ blue light, more than the level considered to be the minimum requirement; thus, further enhancements to a blue light response from non-blue wavelengths would be unlikely.

In tests with lettuce under lamps that were filtered to limit the amount of blue light, Dougher and Bugbee (1999) reported less growth under metal halide than under highpressure sodium lamps, even though the blue light fraction and phytochrome photostationary state were identical. They concluded that nonblue wavelengths from the metal halide lamps, particularly in the range of 570-610 nm, were involved in the response, thus complicating the interpretation of the blue light effects of different radiation sources or lamps. Tests with red and blue LEDs with different peak wavelengths would be useful in determining a blue light response spectrum, without the interactions of non-blue wavelengths. These find-

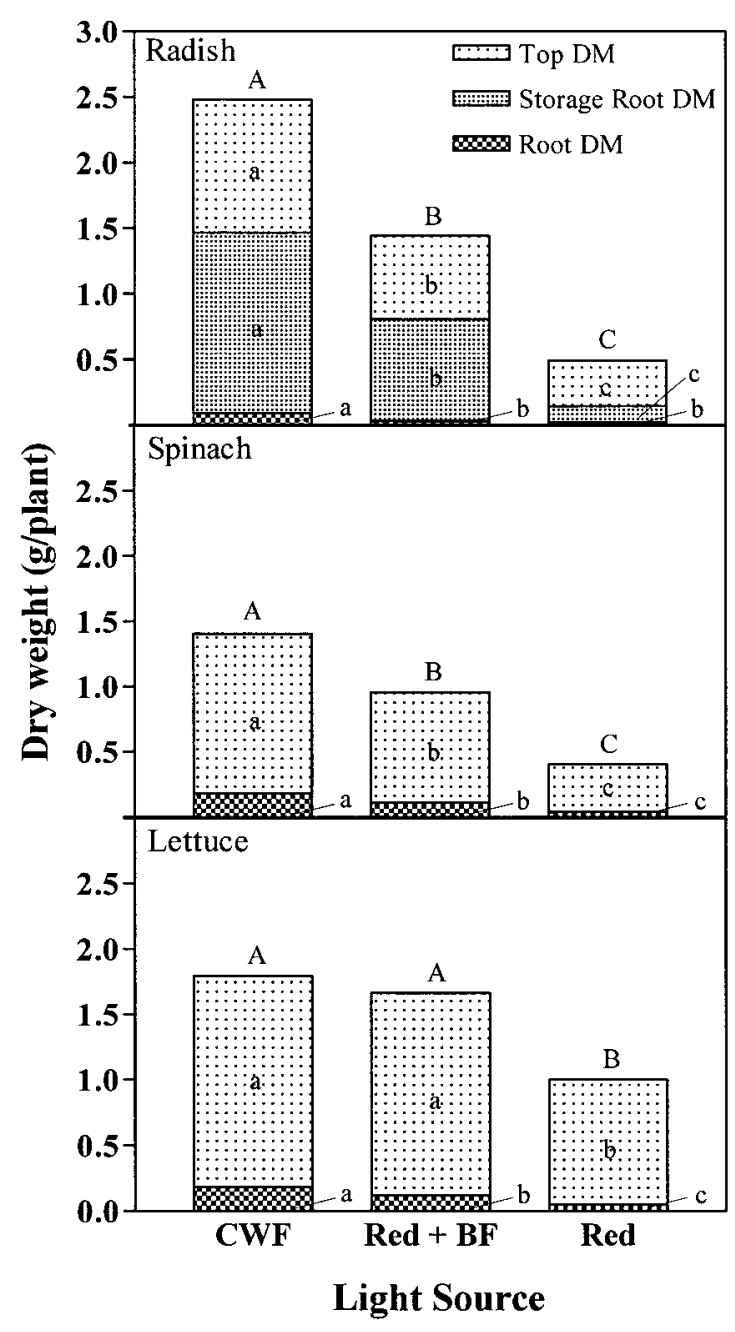

Fig. 2. Dry weight (DW) of top (leaves, petioles, and stem), root, and storage root (radish) of radish, spinach, and lettuce plants grown under cool-white fluorescent $(\mathrm{CWF})$, red LEDs $+10 \%\left(30 \mu \mathrm{mol} \cdot \mathrm{m}^{-2} \cdot \mathrm{s}^{-1} P P F\right)$ blue fluorescent (red $+\mathrm{BF})$, or red LEDs only. Mean separation within species and tissues by Tukey's HSD, $P \leq 0.05$. Capital letters above the bars indicate the significance for total plant DW within species.

Table 2. Effects of light source on single leaf net photosynthesis (Pn), stomatal conductance, and total chlorophyll of radish, spinach, and lettuce plants $21 \mathrm{~d}$ after planting.

\begin{tabular}{|c|c|c|c|}
\hline \multirow[b]{2}{*}{ Measurement } & \multicolumn{3}{|c|}{ Light source } \\
\hline & $\mathrm{CWF}^{\mathrm{z}}$ & $\operatorname{Red}+\mathrm{BF}^{\mathrm{y}}$ & Red LEDs \\
\hline & \multicolumn{3}{|c|}{ Radish } \\
\hline Single leaf $\mathrm{Pn}\left(\mu \mathrm{mol} \mathrm{CO} \mathrm{CO}_{2} \cdot \mathrm{m}^{-2} \cdot \mathrm{s}^{-1}\right)$ & $9.4 \mathrm{a}^{\mathrm{x}}$ & $9.1 \mathrm{ab}$ & $3.8 \mathrm{~b}$ \\
\hline Stomatal conductance $\left(\mathrm{cm} \cdot \mathrm{s}^{-1}\right)$ & $1.3 \mathrm{a}$ & $1.3 \mathrm{a}$ & $1.0 \mathrm{a}$ \\
\hline Total chlorophyll $\left(\mu \mathrm{g} \cdot \mathrm{cm}^{-2}\right)$ & $39.5 \mathrm{a}$ & $26.9 \mathrm{ab}$ & $14.5 \mathrm{~b}$ \\
\hline \multicolumn{4}{|c|}{ Spinach } \\
\hline Single leaf $\mathrm{Pn}\left(\mu \mathrm{mol} \mathrm{CO} \cdot \mathrm{m}^{-2} \cdot \mathrm{s}^{-1}\right)$ & $9.2 \mathrm{a}$ & $10.2 \mathrm{a}$ & $11.0 \mathrm{a}$ \\
\hline Stomatal conductance $\left(\mathrm{cm} \cdot \mathrm{s}^{-1}\right)$ & $0.9 \mathrm{a}$ & $0.8 \mathrm{a}$ & $0.8 \mathrm{a}$ \\
\hline Total chlorophyll $\left(\mu \mathrm{g} \cdot \mathrm{cm}^{-2}\right)$ & $54.1 \mathrm{a}$ & $47.6 \mathrm{ab}$ & $44.5 \mathrm{~b}$ \\
\hline \multicolumn{4}{|c|}{ Lettuce } \\
\hline Single leaf $\mathrm{Pn}\left(\mu \mathrm{mol} \mathrm{CO} \mathrm{CO}_{2} \cdot \mathrm{m}^{-2} \cdot \mathrm{s}^{-1}\right)$ & $7.2 \mathrm{a}$ & $5.9 \mathrm{a}$ & $6.3 \mathrm{a}$ \\
\hline Stomatal conductance $\left(\mathrm{cm} \cdot \mathrm{s}^{-1}\right)$ & $0.4 \mathrm{a}$ & $0.3 \mathrm{a}$ & $0.2 \mathrm{~b}$ \\
\hline Total chlorophyll $\left(\mu \mathrm{g} \cdot \mathrm{cm}^{-2}\right)$ & $25.9 \mathrm{a}$ & $27.9 \mathrm{a}$ & $23.9 \mathrm{a}$ \\
\hline
\end{tabular}

${ }^{\mathrm{z}} \mathrm{CWF}=$ Cool-white fluorescent.

${ }^{y} \operatorname{Red}+\mathrm{BF}=\operatorname{Red}$ LEDs $(660 \mathrm{~nm})+10 \%\left(30 \mu \mathrm{mol} \cdot \mathrm{m}^{-2} \cdot \mathrm{s}^{-1}\right)$ blue fluorescent.

${ }^{x}$ Values within a row followed by different letters are significantly different as determined by ANOVA and Tukey's HSD mean separation test $(P \leq 0.05)$.

ings could then be used to design spectrally balanced LED systems for supporting plant growth.

Yield photon flux (YPF) has been used as a tool for explaining biomass accumulation because it weights photons according to their relative quantum efficiency for photosynthesis (McCree, 1972; Sager et al., 1988). The use of YPF to accurately describe DW accumulation has been demonstrated in wheat (Triticum aestivum L.) and soybean [Glycine $\max$ (L.) Merrill], but not in lettuce grown under broad- 
spectrum lamps with varying blue light fractions (Dougher and Bugbee, 1999). In our tests, $P P F$ was maintained near $300 \mu \mathrm{mol} \cdot \mathrm{m}^{-2} \cdot \mathrm{s}^{-1}$ $P P F$, and YPF was similar for all light treatments (Table 1). Because red photons are the most photosynthetically efficient, YPF was highest in the red LED treatment, yet the DW accumulation for all crops tested was lower under red LEDs than under $\mathrm{CWF}$ and red $+\mathrm{BF}$ (Fig. 2). This suggests that using YPF to compare plant growth between spectrally biased and broad-spectrum sources may not be valid.

Single-leaf photosynthetic rates for radish and stomatal conductance rates for lettuce were lower in plants grown under red LEDs than under either CWF (control) or red LEDs supplemented with BF (Table 2). Lower leaf photosynthetic rates under red LEDs may be associated with lower stomatal conductance, because stomata are controlled more by blue light than by red light (Sharkey and Raschke, 1981; Zeiger, 1984). However, this was not the case for radish or lettuce in our study. Although stomatal conductance was reduced in lettuce under red LEDs, the intercellular $\mathrm{CO}_{2}$ and $\mathrm{Pn}$ rates were similar in all treatments, indicating that carbon assimilation was not affected by stomatal closure. The reduction in Pn for radish grown under red LEDs may be due to a reduced sink demand resulting from the lack of storage root initiation (Bukhov et al., 1996), reduced chlorophyll content (Table 2), or some other physiological requirement for blue light. Although reductions in DW accumulation were similar for all crops grown with red LEDs, only radish showed a reduced $\mathrm{Pn}$; thus, leaf $\mathrm{CO}_{2}$ assimilation rates cannot fully explain the effects. Perhaps the leaves sampled for Pn under red LEDs did not adequately represent the photosynthetic capacity of the entire plant or canopy, especially the lower canopy leaves. Changes in chlorophyll also were not correlated with Pn for spinach grown under red LEDs (Table 2). A possible explanation for the discrepancy between Pn and DW accumulation could lie in the single point Pn measurements in our study. Diurnal Pn and dark respiration measurements of single leaves or whole canopies would be useful in determining the fate of carbon in plants grown under red LEDs.

These studies confirm the notion that red light alone is unacceptable for good growth of lettuce (Barta et al., 1992; Bula et al., 1991), radish, and spinach. The addition of $\approx 30$ $\mu \mathrm{mol} \cdot \mathrm{m}^{-2} \cdot \mathrm{s}^{-1}$ of blue light (400-500 nm) to red LEDs greatly improved growth, but this was still not as good as white light for spinach and radish. Although some effects of light source were noted on rates of leaf photosynthesis and conductance, the effects varied with species and do not appear to fully explain the poor growth under red LEDs. The development and testing of narrow-band blue LEDs in conjunction with red LEDs should provide useful information on blue light effects on plant growth as well as demonstrating the feasibility of using LED technology for growing plants in controlled environments.

\section{Literature Cited}

Barnes, C. and B. Bugbee. 1992. Morphological responses of wheat to blue light. J. Plant Physiol. 139:339-342.

Barnes, C., T. Tibbitts, J. Sager, G. Deitzer, D. Bubenheim, G. Koerner, and B. Bugbee. 1993. Accuracy of quantum sensors measuring yield photon flux and photosynthetic photon flux. HortScience 28:1197-1200.

Barta, D.J., T.W. Tibbitts, R.J. Bula, and R.C. Morrow. 1992. Evaluation of light emitting diode characteristics for space-based plant irradiation source. Adv. Space Res. 12:141-149.

Briggs, W.R. 1993. New light on stem growth Nature 366:110-111.

Britz, S.J. and J.C. Sager. 1990. Photomorphogenesis and photoassimilation in soybean and sorghum grown under broad spectrum or bluedeficient light sources. Plant Physiol. 94:448454.

Brown, C.S., A.C. Schuerger, and J.C. Sager. 1995. Growth and photomorphogenesis of pepper plants under red light-emitting diodes with supplemental blue or far-red lighting. J. Amer. Soc. Hort. Sci. 120:808-813.

Bugbee, B. and F.B. Salisbury. 1988. Exploring the limits of crop productivity. I. Photosynthetic efficiency of wheat in high irradiance environments. Plant Physiol. 88:869-878

Bukhov, N.G., V.V. Bondar, I.S. Drozdova, A.N. Kara, A.A. Kotov, S.N. Maevskaya, A.A. Vasil'ev, S. Yu. Voevudskaya, P. Yu. Voronin, and A.T. Mokronosov. 1996. Development of storage roots in radish (Raphanus sativus) plants as affected by light quality. J. Plant Physiol. 149:405-412.

Bula, R.J., R.C. Morrow, T.W. Tibbitts, D.J. Barta, R.W. Ignatius, and T.S. Martin. 1991. Light emitting diodes as a radiation source for plants. HortScience 26:203-205.

Dougher, T.A.O. and B.G. Bugbee. 1998. Is blue light good or bad for plants? Life Support Biosphere Sci. 5(2):129-136.

Dougher, T.A.O. and B. Bugbee. 1999. Toward an understanding of blue light effects on diverse species: Implications for advanced life-support systems. SAE Tech. Paper 1999-01-2108.

Goins, G.D., N.C. Yorio, M.M. Sanwo, and C.S. Brown. 1997. Photomorphogenesis, photosynthesis, and seed yield of wheat plants grown under red light-emitting diodes (LEDs) with and without supplemental blue lighting. J. Expt. Bot. 48:1407-1413.

Goins, G.D., N.C. Yorio, M.M. Sanwo-Lewandowski, and C.S. Brown. 1998. Life cycle experiments with Arabidopsis grown under red light-emitting diodes (LEDs). Life Support Biosphere Sci. 5(2):143-150.

Graves, C.J. 1981. The nutrient film technique. Hort. Rev. 5:1-43.

Hoagland, D.R. and D.I. Arnon. 1950. The water culture method for growing plants without soil. California Agr. Expt. Stat. Circ. 347.

Hoenecke, M.E., R.J. Bula, and T.W. Tibbitts. 1992. Importance of "blue" photon levels for lettuce seedlings grown under red light-emitting diodes. HortScience 27:427-430.

Langhans, R.W. and D.R. Dreesen. 1988. Challenges to plant growing in space. HortScience 23:286-293.

MacElroy, R.D. and J. Bredt. 1985. Current concepts and future direction in CELSS, p. 1-9. In: Life support systems in space travel. NASA Conf. Publ. 2378, Moffett Field, Calif.

McCree, K.J. 1972. The action spectrum, absorptance and quantum yield of photosynthesis in crop plants. Agr. Meteorol. 9:191-216.

Olson, R.L., M.W. Oleson, and T.J. Slavin. 1988. CELSS for advanced manned missions. HortScience 23:275-286.

Sager, J.C., W.O. Smith, J.L. Edwards, and K.L. Cyr. 1988. Photosynthetic efficiency and phytochrome photoequilibria determination using spectral data. Trans. Amer. Soc. Agr. Eng. 31:1882-1889.

Sager, J.C. and R.M. Wheeler. 1992. Application of sunlight and lamps for plant irradiation in space bases. Adv. Space Res. 12:133-140.

Salisbury, F.B. and B. Bugbee. 1988. Plant productivity in controlled environments. HortScience 23:293-299.

Salisbury, F.B. and M.A. Clark. 1996. Suggestions for crops grown in a controlled environment life-support systems, based on attractive vegetarian diets. Adv. Space Res. 18:33-39.

Senger, H. 1984. Blue light effects in biological systems. Springer-Verlag, Berlin.

Sharkey, T.D. and K. Raschke. 1981. Effect of light quality on stomatal opening in leaves of Xanthium strumarium L. Plant Physiol. 68:1170-1174.

Wheeler, R.M., C.L. Mackowiak, and J.C. Sager. 1991. Soybean stem growth under high-pressure sodium with supplemental blue lighting. Agron. J. 83:903-906.

Wintermans, J.F.G.M. and A. De Mots. 1965. Spectrophotometric characteristics of chlorophylls a and $b$ and their pheophytins in ethanol. Biochem. Biophys. Acta 109:448-453.

Yorio, N.C, C.L. Mackowiak, R.M. Wheeler, and J.C. Sager. 1995. Vegetative growth of potato under high-pressure sodium, high-pressure sodium SON-Agro, and metal halide lamps. HortScience 30:374-376.

Yorio, N.C., R.M. Wheeler, G.D. Goins, M.M. Sanwo-Lewandowski, C.L. Mackowiak, C.S. Brown, J.C. Sager, and G.W. Stutte. 1998. Blue light requirements for crop plants used in bioregenerative life support systems. Life Support Biosphere Sci. 5(2):119-128.

Zeiger, E. 1984. Blue light and stomatal function, p. 484-494. In: H. Senger (ed.). Blue light effects in biological systems. Springer-Verlag, Berlin. 